Molecules 2004, 9, 860-866

molecules

ISSN 1420-3049

http://www.mdpi.org

\title{
Synthesis and Spectroscopic Characterization of New Schiff Bases Containing the Benzo-15-Crown-5 Moiety
}

\author{
Zeliha Hayvalı $^{1}{ }^{1 *}$, Mustafa Hayvalı ${ }^{1}$ and Hakan Dal ${ }^{2}$ \\ ${ }^{1}$ Ankara University, Department of Chemistry, Faculty of Science, 06100, Tandoğan, Ankara, Turkey. \\ ${ }^{2}$ Anadolu University, Department of Chemistry, Faculty of Science, Eskişehir, Turkey. \\ * Author to whom correspondence should be addressed; e-mail: zhayvali@science.ankara.edu.tr; Tel: \\ (+90) 3122126720 .
}

Received: 4 June 2004 / Accepted: 19 July 2004 / Published: 30 September 2004

\begin{abstract}
New crown ether Schiff base derivatives were prepared by the condensation of 4'-formylbenzo-15-crown-5 or 4'-formyl-5'-hydroxybenzo-15-crown-5 with 1,2-bis(2aminophenoxy)ethane. The structures of these new compounds were confirmed on the basis of elemental analysis, IR, ${ }^{1} \mathrm{H}-$ and ${ }^{13} \mathrm{C}-\mathrm{NMR}, \mathrm{UV}-\mathrm{V}$ is and mass spectroscopic data.
\end{abstract}

Keywords: Crown ether, Schiff base, Spectroscopy.

\section{Introduction}

Macrocyclic polyethers like crown ethers have received much attention in the last few years, both in chemistry and in biology [1-3]. Some crown ethers play an important role in membrane separation processes [4], fibre optic chemical sensor properties [5] and phase transfer catalysis [6,7]. In addition, owing to the recognition of the complexation properties of macrocyclic polyethers with alkali, alkaline-earth metal cations and uncharged organic molecules, considerable work has been done in the macrocyclic polyethers area [8-10]. Crown ethers featuring salicyclic Schiff base ligands form the basis of an extensive class of chelating ligands that have enjoyed widespread use in the coordination chemistry of the transition and main group elements [11-14]. On the other hand, the extent of the 
interaction of hard cations with transition metal centers, monitoring the redox and electronic properties of the transition metal ions and these complexes can ultimately be used as sensors (electrochemical and electronic) for alkaline, alkaline-earth and lanthanide metal ions [15-17].

In the present paper we report the preparation of two new compounds, 6 and 7 , by the condensation of 1,2-bis(2-amino-phenoxy)ethane (5) with 4'-formylbenzo-15-crown-5 (2) and 4'-formyl-5'hydroxybenzo-15-crown-5 (4) and their characterization by spectral data (IR, ${ }^{1} \mathrm{H}-$ and ${ }^{13} \mathrm{C}-\mathrm{NMR}$, UVVis and MS).

\section{Results and Discussion}

The starting compounds and crown ether Schiff base have been synthesized in several steps as depicted in Scheme 1.

Scheme 1
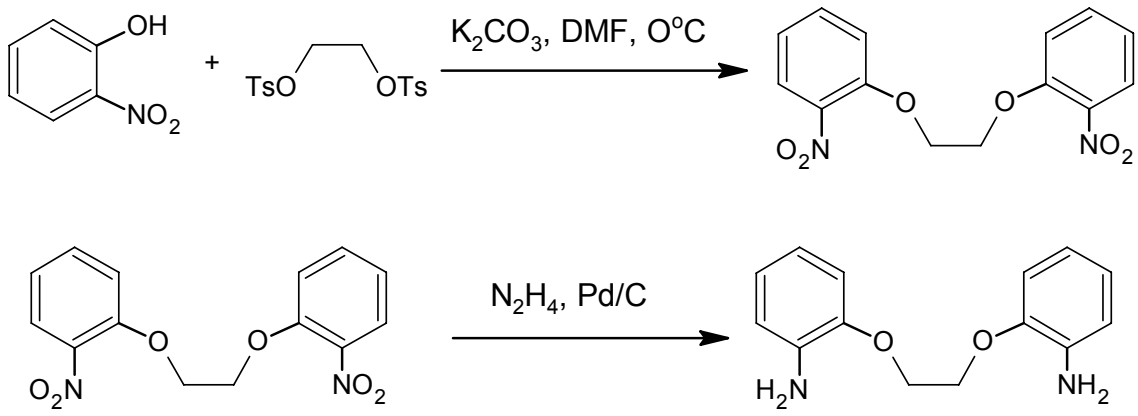

(5)<smiles>Cc1cccc(OCCOc2ccccc2N)c1N</smiles>

(2)

(5)

(6)<smiles>Cc1cccc(OCCOc2cccc(C=O)c2N)c1N</smiles> 

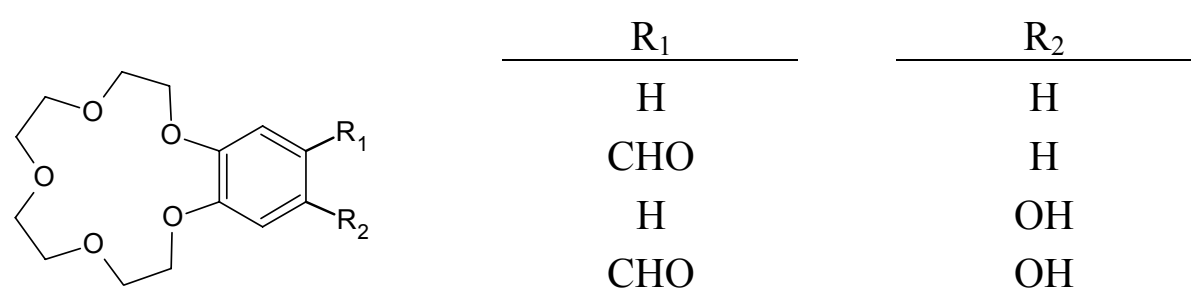

Comp.

The new crown ether Schiff bases were prepared from equimolar amounts of aldehyde and diamine. The spectral data indicate that one arm of the diamine remains free in the Schiff base ligands as the IR spectra of the Schiff bases 6 and 7 showed the characteristic free amine stretching bands $v_{\left(\mathrm{NH}_{2}\right)}$ at 3478-3365 $\mathrm{cm}^{-1}$ and 3484-3364 $\mathrm{cm}^{-1}$, respectively. The imine stretching bands attributable to the azomethine group $(\mathrm{CH}=\mathrm{N})$ were seen at $1621 \mathrm{~cm}^{-1}$ for compound 6 and $1617 \mathrm{~cm}^{-1}$ for compound 7. In the spectra of compound 7 the phenolic $\mathrm{OH}$ group stretching band was not observed, indicating the formation of a cyclic intramolecular hydrogen bond. But in the ${ }^{1} \mathrm{H}-\mathrm{NMR}$ spectra of the same ligand, the $\mathrm{OH}$ proton was observed at $14.12 \mathrm{ppm}$. The azomethine $(\mathrm{CH}=\mathrm{N})$ protons for compounds 6 and 7 were seen at $8.38 \mathrm{ppm}$ and $8.60 \mathrm{ppm}$, respectively. The signals of the crown ether protons of both ligands are seen as multiplets at 3.96-3.76 ppm and 4.07-3.81 ppm, respectively. In the ${ }^{13} \mathrm{C}$ decoupled NMR spectra of the crown ether Schiff bases 6 and 7, eight crown ether and amine group ether carbons were observed between 71.7-68.0 ppm and 71.5-67.7 ppm respectively. Azomethine carbons and aromatic carbons were also detected and identified. In the mass spectra (EI) of $\mathbf{6}$ and $\mathbf{7}$ the molecular ion peaks $\left[\mathrm{M}^{+}\right]$were not observed, but important fragments were observed, confirming the proposed

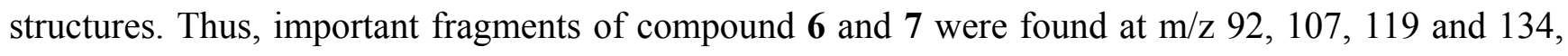
which correspond to the fragments [ $\left.\left(\mathrm{HOCH}_{2} \mathrm{CH}_{2} \mathrm{OCH}_{2} \mathrm{CH}_{3}\right)+2 \mathrm{H}\right],\left[\left(\mathrm{HOCH}_{2} \mathrm{CH}_{2} \mathrm{OCH}_{2} \mathrm{CH}_{2} \mathrm{OH}\right)+\mathrm{H}\right]$, $\left(\mathrm{HOCH}_{2} \mathrm{CH}_{2} \mathrm{OCH}_{2} \mathrm{CH}_{2} \mathrm{OCH}_{2}\right)$ and $\left(\mathrm{HOCH}_{2} \mathrm{CH}_{2} \mathrm{OCH}_{2} \mathrm{CH}_{2} \mathrm{OCH}_{2} \mathrm{CH}_{3}\right)$, respectively.

The fragmentation pattern shows that the ether chains are fragile under the experimental conditions. Other important fragments of compound 6 were found at $\mathrm{m} / \mathrm{z} 243,387$ and 414 and of compound 7 at $\mathrm{m} / \mathrm{z} 244$ and 322. These fragmentation patterns proceeding by the loss of ether chain segments are in accordance with the literature [12,13,18-21]. In previous papers we reported tautomeric equilibria (phenol-imine, $\mathrm{O}-\mathrm{H}^{\cdots \cdots} \mathrm{N}$ and keto-amine, $\mathrm{O} \cdots \mathrm{H}-\mathrm{N}$ forms) to be present in featuring salicyclic Schiff base derivatives depending on the formation intramolecular hydrogen bonding by UV-Vis spectra. In solution, the tautomerism depends on solvent polarity [12,13,20,21-25]. For instance, in polar solvents, a new band at $>400 \mathrm{~nm}$ arises, whereas this can not be observed in nonpolar solvents. The UV-Vis spectra of compound 7 was only recorded in $\mathrm{CHCl}_{3}$ because it was not sufficiently soluble in other solvents tested $\left(\mathrm{EtOH}\right.$ and $\left.\mathrm{C}_{6} \mathrm{H}_{12}\right)$. The spectra indicate that the keto-amine tautomeric form is present. In $\mathrm{CHCl}_{3}$ one additional band appears at $422 \mathrm{~nm}\left(\mathrm{n}-\pi^{*}\right)$, which has been linked with the shift of the tautomeric equilibrium to the keto-amine form. 


\section{Conclusions}

In this paper we describe the synthesis of two new benzo-15-crown-5 Schiff base ligands, 6 and 7 , by reaction of 1,2-bis(2-aminophenoxy)ethane with 4'-formylbenzo-15-crown-5 and 4'-formyl-5'hydroxybenzo-15-crown-5, respectively. Our motive behind the synthesis of this type of the ligands was to examine their possible applications in cation recognition processes, as homo- or heteronuclear complexes can be synthesized from alkali and transition metal cations and these complexes may also serve as models of relevance to bioinorganic chemistry such as metalloenzymes.

\section{Acknowledgements}

The authors gratefully acknowledge the financial assistance of the Research Foundation of Ankara University (Project No. 20020705070).

\section{Experimental}

\section{General}

All solvents were from Merck and all other reagents from Aldrich; all were used without further purification. Melting points were measured with a Thomas-Hoover apparatus using a capillary tube. Elemental analyses were performed on a Leco CHNS-932C instrument. IR spectra in the 400-4000 $\mathrm{cm}^{-1}$ region were recorded on a Mattson 1000 FTIR spectrometer using $\mathrm{KBr}$ pellets. ${ }^{1} \mathrm{H}-$ and ${ }^{13} \mathrm{C}-\mathrm{NMR}$ (400 MHz) spectra were recorded on a Bruker DPX FT-NMR spectrometer in $\mathrm{CDCl}_{3}$, using the solvent peaks of $\mathrm{CDCl}_{3},(\delta=7.26)$ and $\mathrm{CDCl}_{3},(\delta=77.00)$ as the internal locks. Chemical shifts are reported in ppm relative to TMS, used as internal standard. UV-Vis spectra were measured using a UNICAM UV2-100 series spectrometer. Mass spectra were obtained on a VG-ZAPSPEC spectrometer according to electron impact (EI, $70 \mathrm{eV})$.

\section{Syntheses}

The starting compounds 1-5 and crown ether Schiff bases 6 and 7 were prepared in several steps as depicted in Scheme 1. Benzo-15-crown-5 (1) was synthesized according to the procedure of Pedersen [26]. 4'-Formylbenzo-15-crown-5 (2) was synthesized from 1 under Vilsmeier-Hack conditions and purified via the corresponding bisulfite-adduct [27]. 4'-Formyl-5'-hydroxybenzo-15-crown-5 (4) was synthesized from 3 according to the literature method [29]. 1,2-bis(2-nitrophenoxy)ethane and 1,2bis(2-amino-phenoxy)ethane (5) were prepared according to the literature methods [30,31]. 
4'-Hydroxybenzo-15-crown-5 (3)

This compound was synthesized from $\mathbf{2}$ according to a modification of the reported procedure [28]. The improvements allow isolation of the title compound as a white crystalline powder rather than as an oil. A solution of $m$-chloroperoxybenzoic acid $(2.10 \mathrm{~g}, 13.5 \mathrm{mmol})$ in dichloromethane $(20 \mathrm{~mL})$ was added dropwise with stirring at $0{ }^{\circ} \mathrm{C}$ to a solution of 4'-formylbenzo-15-crown-5 (2, $\left.2.01 \mathrm{~g}, 6.8 \mathrm{mmol}\right)$ in dichloromethane $(30 \mathrm{~mL})$. The mixture was then stirred for $60 \mathrm{~h}$. at room temperature. To neutralize the $m$-chlorobenzoic acid formed a solution of $10 \% \mathrm{NaHCO}_{3}(3 \times 25 \mathrm{~mL})$ was added with stirring to the reaction mixture. The dichloromethane phase was separated and concentrated under reduced pressure. The residue was diluted with THF $(10 \mathrm{~mL})$ and concentrated hydrochloric acid $(4 \mathrm{~mL})$ was added. The mixture was stirred for $4 \mathrm{~h}$. at room temperature, diluted with water and extracted with chloroform. The chloroform layer was dried over magnesium sulfate and concentrated under reduced pressure. The residue was purified by chromatography on a silica gel column (eluent: 1:9 methanol/chloroform) to afford 3 as a white powder. Yield (1.24 g, 64\%); m.p. $103{ }^{\circ} \mathrm{C}$; Anal. Calcd. For $\mathrm{C}_{14} \mathrm{H}_{20} \mathrm{O}_{6}$ : C, 59.14; H, 7.09; Found: C, 59.01; H, 6.90; ${ }^{1} \mathrm{H}-\mathrm{NMR}$ : $\delta$ 6.72-6.20 (m, 3H, arom. $\left.\mathrm{H}\right)$, 4.24-3.52 (m, 16H, OCH $)$; IR $v / \mathrm{cm}^{-1}: 3478,3165(\mathrm{OH}), 2978,2933,2896,1621$ (arom.), 1525 (arom.), 1468, 1363, 1299, 1238 (aryl. C-O), 1180, 1138 (alkyl. C-O).

4'-Formylbenzo-15-Crown-5 with 1,2-Bis(2-aminophenoxy)ethane Schiff Base (6)

4'-Formylbenzo-15-crown-5 (2) (0.50 g; $1.68 \mathrm{mmol})$ was dissolved in methanol (50 mL) and this solution was added dropwise to a methanolic solution $(25 \mathrm{~mL})$ of 1,2-bis(2-aminophenoxy)ethane $(0.40 \mathrm{~g} ; 1.68 \mathrm{mmol})$. The mixture was refluxed for $1 \mathrm{~h}$ and then allowed to cool to ambient temperature. The bright yellow crystals formed were filtered off and left to dry in open air. Yield $0.57 \mathrm{~g}(64.7 \%)$; m.p. $135{ }^{\circ} \mathrm{C}$; Anal. Calcd. For $\mathrm{C}_{29} \mathrm{H}_{34} \mathrm{O}_{7} \mathrm{~N}_{2}$ : C, 66.66; H, 6.51; N, 5.36. Found: C, 66.64; H, 6.30; N, 5.21; ${ }^{1} \mathrm{H}-\mathrm{NMR}: \delta 8.38(\mathrm{~s}, 1 \mathrm{H}, \mathrm{HC}=\mathrm{N}), 7.62(\mathrm{q}, J=8.2 \mathrm{~Hz}, J=1.8 \mathrm{~Hz}, 1 \mathrm{H}$, arom. H), 7.15-7.00 (m, 4H, arom. H), 6.90-6.77 (m, 4H, arom. H), $6.71(\mathrm{~d}, J=1.8 \mathrm{~Hz}, 1 \mathrm{H}$, arom. H), $6.64(\mathrm{~d}, J=8.2 \mathrm{~Hz}, 1 \mathrm{H}$, arom. $\mathrm{H}), 4.34\left(\mathrm{~m}, 4 \mathrm{H}, \mathrm{OCH}_{2}\right), 4.17\left(\mathrm{~s}, 2 \mathrm{H},-\mathrm{NH}_{2}\right), 3.96-3.76\left(\mathrm{~m}, 16 \mathrm{H},-\mathrm{CH}_{2}\right) ;{ }^{13} \mathrm{C}-\mathrm{NMR}: \delta 161.6$ $(\mathrm{HC}=\mathrm{N}), 155.1,152.6,151.6,149.8,146.7,143.2,137.3,130.5,127.2,126.5,124.7,122.3,121.4$, 118.5, 115.7, 114.4, 112.3, 111.9 (arom. C), 71.7, 71.6, 70.9, 69.9, 69.7, 69.3, 69.2, 68.7, 68.6, 68.0 $\left(\mathrm{O}-\mathrm{CH}_{2}\right)$; IR v/cm ${ }^{-1}$ : 3478, $3365\left(\mathrm{NH}_{2}\right), 2925,2865$ (aliph. $\mathrm{CH}$ ), $1621(\mathrm{C}=\mathrm{N}), 1274$ (arom. C-O-C), 1120-1047 (aliph. C-O-C); UV-Vis (EtOH). $\lambda_{\max } / \mathrm{nm}\left(\varepsilon / \mathrm{dm}^{3} \mathrm{~mol}^{-1} \mathrm{~cm}^{-1}\right): 282$ (33980), 314 (27080); MS (EI) $\mathrm{m} / \mathrm{z}: 414,387,243,134,119,107$ and 92).

4'-Formyl-5'-Hydroxybenzo-15-Crown-5 with 1,2-Bis(2-aminophenoxy)ethane Schiff Base (7)

A solution of 4'-formyl-5'-hydroxybenzo-15-crown-5 (4) (0.50 g; $1.60 \mathrm{mmol})$ in dry methanol (50 $\mathrm{mL}$ ) was added dropwise to a solution of 1,2-bis(2-aminophenoxy)ethane $(0.39 \mathrm{~g} ; 1.60 \mathrm{mmol})$ in methanol $(50 \mathrm{~mL})$. The mixture was refluxed for $1 \mathrm{~h}$ and then cooled to ambient temperature. The light 
yellow powder that precipitated from the methanol was collected and recrystallized from acetonitrile. Yield 0.53 g (58.8 \%); m.p. $146{ }^{\circ} \mathrm{C}$; Anal. Calcd. for $\mathrm{C}_{29} \mathrm{H}_{34} \mathrm{O}_{8} \mathrm{~N}_{2}$ : C, 64.68; H, 6.31; N, 5.20. Found: C, 64.60; H, 6.04; N, 5.52; ${ }^{1} \mathrm{H}-\mathrm{NMR}: \delta 14.47(\mathrm{~s}, 1 \mathrm{H}, \mathrm{OH}), 8.60(\mathrm{~s}, 1 \mathrm{H}, \mathrm{HC}=\mathrm{N}), 7.26(\mathrm{~m}, 2 \mathrm{H}$, arom. H), $7.08(\mathrm{~m}, 2 \mathrm{H}$, arom. H), $6.89(\mathrm{~m}, 2 \mathrm{H}$, arom. $\mathrm{H}), 6.80(\mathrm{~s}, 1 \mathrm{H}$, arom. H), $6.73(\mathrm{~m}, 2 \mathrm{H}$, arom. $\mathrm{H}), 6.48(\mathrm{~s}$, $1 \mathrm{H}$, arom. $\mathrm{H}), 4.47\left(\mathrm{~m}, 4 \mathrm{H}, \mathrm{OCH}_{2}\right), 4.20\left(\mathrm{~s}, 2 \mathrm{H},-\mathrm{NH}_{2}\right), 4.07-3.81\left(\mathrm{~m}, 16 \mathrm{H},-\mathrm{CH}_{2}\right) ;{ }^{13} \mathrm{C}-\mathrm{NMR}: \delta 162.3$ $(\mathrm{HC}=\mathrm{N}), 160.4,155.7,151.8,146.4,141.9,137.5,137.0,127.3,122.3,120.3,118.6,117.5,115.7$, 114.2, 113.2, 112.9, 111.6, 102.3 (arom. C), 71.5, 71.3, 71.1, 71.0, 70.6, 70.2, 69.5, 68.6, 67.9, 67.7 $\left({\mathrm{O}-\mathrm{CH}_{2}}_{2}\right)$; IR $v / \mathrm{cm}^{-1}:$ 3484, $3364\left(\mathrm{NH}_{2}\right), 2928,2873$ (aliph. $\mathrm{CH}$ ), $1617(\mathrm{C}=\mathrm{N}), 1270$ (arom. C-O-C), 1116-1045 (aliph. C-O-C); UV-Vis $\left(\mathrm{CHCl}_{3}\right) . \lambda_{\max } / \mathrm{nm}\left(\varepsilon / \mathrm{dm}^{3} \mathrm{~mol}^{-1} \mathrm{~cm}^{-1}\right): 322$ (8740), 422 (7040); MS (EI) $\mathrm{m} / \mathrm{z}: 322,244,135,119,107$ and 92).

\section{References}

1. Samara, C. D.; Alevizopoulou, L.; Iordanidis, L.; Samaras, E.; Kessissoglou, D. P. J. Inorg. Biochem. 2002, 89, 89.

2. Wang, D.; Xing, J.; Peng, J.; Wu, C. J. Chromatogr. A 2003, 1005, 1.

3. Yi, Y.; Wang, Y.; Liu, H. Carbohydr. Polym. 2003, 53, 425.

4. Flyes, T. M.; Whiffield, D. M. Can. J. Chem. 1984, 62, 507.

5. Blair, T. L.; Cynkowski, T., Bachas, L. G. Anal. Chem. 1993, 65, 945.

6. Kudo, Y.; Usami, J.; Katsuta, S.; Takeda, Y. Talanta 2003, 59, 1213.

7. Watanabe, H.; Iijima, T.; Fukuda, W.; Tomoi, M. React. Funct. Polym. 1988, 37, 101.

8. Liddle, S. T.; Clegg, W. Polyhedron 2003, 22, 3507.

9. Steed, J. W. Coord. Chem. Rev. 2001, 215, 171.

10. Hill, S. E.; Feller, D. Int. J. Mass Spectrom. 2000, 201, 41.

11. Casellato, U.; Tamburini, S.; Tomasin, P.; vigato, P. A. Inorg. Chim. Acta 2002, 341, 118.

12. Hayvalı, Z.; Gündüz, N.; Kılıç, Z.; Weber, E. J. Prakt. Chem. 1999, 341, 568.

13. Hayvalı, Z.; Gündüz, N.; Kılıç, Z.; Weber, E. Z. Naturforsch. B: Chem Sci. 2000, 55, 975.

14. Beer, P. D.; Christopher, G. C.; Drew, M. G. B. J. Chem. Soc. Dalton Trans. 1991, 3235.

15. Beer, P. D. Adv. Inorg. Chem. 1992, 39, 79.

16. Beer, P. D.; Gale, P. A.; Chen, G. V. Coord. Chem. Rev. 1992, $39,79$.

17. Beer,P. D.; Tite, E. L.; Ibbotson, A. J. Chem. Soc. Dalton Trans 1990, 2691.

18. Fenton, D. E. Perkin D. J. Chem. Soc. Perkin Trans. 1981, $1,49$.

19. Hayvalı, Z.; Hayvalı, M.; Kılıç, Z.; Hökelek, T. J. Mol. Struct. 2001, 597, 223.

20. Hayvalı, Z.; Hayvalı, M.; Kılıç, Z.; Hökelek, T. J. Inclusion Phenom. Macrocycl. Chem. 2003, $45,285$.

21. Hayval1, M.; Hayval1, Z. Synt. React. Inorg. Met.-Org. Chem. 2004, 34, 713.

22. Yıldız, M.; K1lıc, Z.; Hökelek, T. J. Mol. Struct. 1998, 441.

23. Salman, S. R.; Shawkat, S. H.; Al Obaidi, G. M. Can. J. Spectrosc. 1989, 35, 25. 
24. Dziembowska, T.; Jagodzinska, E.; Rozwadowski, Z.; Kotfica, M. J. Mol. Struct. 2001, 598, 229.

25. Hayval1, Z. Asian J. Chem. 2003, 15, 877.

26. Pedersen, C. J. J. Am. Chem. Soc. 1967, 89, 7017.

27. Hyde, E. M.; Shaw, B. L.; Shepherd, I. J. Chem. Soc. Dalton Trans. 1978, 1969.

28. Camps, F.; Coll, J.; Ricart, S. J. Heterocycl. Chem. 1983, 20, 249.

29. Can, S.; Bekaroğlu, Ö. J. Chem. Soc. Dalton Trans. 1988, 2831.

30. Balcom, D.; Forst, A. J. Chem. Soc. 1953, 75, 4334.

31. Cannon, R. D.; Chiswell, B.; Venanzi, M. J. Chem. Soc. 1967, 1277.

Sample availability: Available from the authors.

(C) 2004 by MDPI (http://www.mdpi.org). Reproduction is permitted for noncommercial purposes. 